\title{
PALABRAS DEL DOCTOR MARIO MELGAR ADALID, EN LA PRESENTACIÓN DEL NÚMERO CONMEMORATIVO DEL DÉCIMO ANIVERSARIO DE CUESTIONES CONSTITUCIONALES, REVISTA MEXICANA DE DERECHO CONSTITUCIONAL. TRIBUNAL SUPERIOR DE JUSTICIA DEL DISTRITO FEDERAL
}

Es un privilegio participar en la presentación del número conmemorativo del décimo aniversario de Cuestiones Constitucionales, Revista Mexicana de Derecho Constitucional. Como lo es ser miembro fundador de su Consejo Editorial, gracias a la invitación que me formulara hace 10 años el doctor Diego Valadés, entonces director del Instituto de Investigaciones Jurídicas de la UNAM. Es un privilegio haber publicado artículos en diversos números. Gracias al doctor Edgar Corzo, director de la revista por dirigir este vehículo tan relevante de las cuestiones constitucionales.

El título del artículo publicado en el número que hoy conmemoramos en esta magna sede del H. Tribunal de Justicia del Distrito Federal, gracias a la invitación de su presidente el doctor Edgar Elías Azar, fue "La Suprema Corte de Obama". La intención del artículo fue dar algunas líneas sobre el papel de la Suprema Corte en la organización política, jurídica, social y económica de los Estados Unidos. El artículo se complementó con otro de Geraldina González de la Vega "La importancia de la Presidencia de Barack Obama para la Constitución de Estados Unidos". Este texto aparece en la sección comentarios jurisprudenciales. la revista tiene cuatro apartados: artículos, comentarios jurisprudenciales, comentarios legislativos y reseñas bibliográficas. El acervo que se ha reunido en estos diez años constituye una enciclopedia del derecho constitucional mexicano y comparado.

Al momento de la publicación del artículo de Geraldina González de la Vega y del mío, Barak Obama había nominado por primera vez a quien debería ocupar al vacante que dejaría David Souter juez asociado de la 
Corte. Souter decidió retirarse para ir a descansar a su cabaña en las montañas. Souter es un personaje singular. Nunca le gustó Washington. A pesar de ser un hombre rico, después de años de trabajo profesional como abogado y como juez, vivía como un anacoreta: llevaba su almuerzo a la Corte consistente en manzanas y yogurt. Vivía en un departamento pequeño, sin decoración y después de muchos años de trabajo, decidió retirarse para ir a su cabaña en New Hampshire. Ahora se dedica a leer y caminar por las montañas. La nominación de quien debería de sustituirlo recayó en la juez de apelación, Sonia Sotomayor, que fue evaluada por el Senado y finalmente designada. De entonces a la fecha han sucedido cosas que el artículo ya no pudo referir y que me pareció que sería oportuno comentar en esta presentación, en lugar de ajustarme a glosar el artículo publicado.

Hace unas semanas, el juez John Paul Stevens tomó el avión que lo trasladaría a Washington DC, ciudad a la que arribaría al anochecer. Cansado, después de llegar a casa se dispuso a preparar el proyecto de resolución judicial que debería que rendir a la mañana siguiente. No le gustaba dejar asuntos relevantes en manos de los secretarios. Se trataba de definir el monto que podrían dedicar las empresas o los sindicatos a las campañas para apoyar a los políticos de sus preferencias o para ir en contra de algún candidato no deseado. El asunto se conoce como Citizen United vs. FEC y es un asunto de especial significación. Terminó el texto a la medianoche. A las nueve mañana estaba programada su intervención ante el pleno de la Suprema Corte. Antes de eso, a las seis, había concertado un partido de tenis.

Al iniciar la lectura de su ponencia los párrafos se confundían y las luces de los reflectores dirigidas al podium lo deslumbraban. No podía leer el proyecto de resolución. Estaba confundido. En mal estado físico, apenas pudo concluir la atropellada e indescifrable lectura del texto. John Paul Stevens, juez asociado de la Suprema Corte de Justicia (nosotros les decimos ministros) percibió que había llegado la hora que sujeta todo horario, la hora de retirarse. En unos días cumpliría 92 años. Stevens envío una carta al presidente Obama anunciando su decisión de retirarse del cargo para el que fue nombrado de por vida. La noticia ocupó las primeras planas de los todos diarios y algunos como el New York Times, reprodujeron la carta de retiro en primera plana. 
Como las elecciones intermedias están a la vista (noviembre de 2010) y no se sabe si los demócratas conservarán la exigua mayoría en el Senado, el presidente Obama apresuró la nominación con el fin de que el Senado vote antes de los comicios. Propuso a Elena Kagan, actualmente la Solicitor General, una oficina de enlace del gobierno federal con la Suprema Corte. Esta oficina, tan cercana a la Suprema Corte, ocupa un espacio en el mismo edificio que alberga a la Corte, tiene entre sus facultades participar como amicus curiae, amigo del Tribunal, figura del derecho romano que es tan común en los juicios estadounidenses, o bien para presentar la defensa a la acción del gobierno federal. En ciertos casos función similar a la que hacen los ministerios de justicia en Europa en la relación entre el gobierno y el Poder Judicial. La nominada nunca ha ocupado un cargo judicial.

La nominación ha generado un debate doble en los medios judiciales y académicos de Estados Unidos. Al irse el Juez Asociado Stevens, que es protestante, si se designa a Kagan que es judía, no habría, por primera ocasión en la historia de la Suprema Corte de Estados Unidos, un solo protestante en la Suprema Corte de un país que es históricamente protestante. Además, la Corte ha estado integrada hace años, por quienes fueron previamente jueces de apelación en las cortes federales. La llegada de una externa ha provocado suspicacias, pues el gremio judicial es particularmente celoso de intromisiones ajenas.

Otros piensan que la llegada de una mujer con origen académico, directora de la Escuela de Derecho de la Universidad de Harvard y profesora muy destacada, le dará nuevos aires a la Corte que parece atada al pasado. Obama ha criticado algunas de las decisiones de la Corte. Recientemente lo hizo en Citizen United vs. FEC sobre el gasto en campañas de las empresas, asunto en el que Stevens fue derrotado por los conservadores. Este asunto lo defendió Kagan ante la Corte, sin suerte, y tuvo un enfrentamiento verbal, áspero y agrio con Scalia, el ultraconservador juez asociado. Ya circulan distintas versiones de que tan áspera será la relación de Elena Kagan, de ser nominada, con su colega Scalia que la llegó a interrumpir abruptamente en su defensa de la postura del gobierno en el asunto en que la Corte resolvió que no hay límites a los gastos de empresas y sindicatos para favorecer o perjudicar a un candidato político. 
Kagan tendrá la oposición de quienes piensan que la Suprema Corte deben ocuparla quienes fueron jueces. Esta práctica desvirtúa el sistema judicial de los Estados Unidos en que históricamente jueces, abogados y profesores integraban un cuerpo colegiado en que las procedencias y diversas experiencias de los integrantes enriquecen la visión y contribuyen de mejor manera a alcanzar la pluralidad de enfoques y perspectivas.

La Suprema Corte de los Estados Unidos ha estado integrada desde hace años por conservadores que no aceptan apartarse del texto original de la Constitución y sus enmiendas. Los liberales por el contrario, estiman que la Constitución es lo que la Corte dice que debe ser. Apenas esta semana (tercera semana de mayo 2010) en el caso Graham vs. Florida la Suprema Corte sostuvo que la prohibición de la Enmienda Octava sobre penas crueles y exorbitantes prohíbe la cadena perpetua de menores que no hayan participado en homicidios. En 2005 la Corte sostuvo que la Octava Enmienda prohíbe la ejecución de menores infractores. Este asunto muestra que no todo es admirable de la justicia estadounidense. En ese país existen al momento más de 2000 menores cumpliendo condenas de cadena perpetua, lo que no acontece en ningún país del mundo. En diciembre la ONU resolvió a favor de la abolición de cadenas perpetuas, sin posibilidad de conmutación de la pena para niños y adolescentes. La votación fue 185 países a favor uno en contra: los Estados Unidos: el disidente solitario.

En las confirmaciones ante el Senado de los Jueces Asociados, que hace unos días votaron en contra de la resolución, John G. Roberts y Samuel Alito señalaron que era un grave error de la Suprema Corte de Estados Unidos tomar en cuenta el derecho internacional al resolver los casos que se les presentan. No obstante en este asunto el juez asociado Anthony Kennedy invocó el derecho internacional al formular la resolución que adoptaría la mayoría. El chief justice, John Roberts, estuvo de acuerdo en este asunto, pero no con la idea del ponente Kennedy que la resolución tuviera efectos generales, sino que se revisará caso por caso para determinar si quienes cumplen sentencias por delitos cometidos cuando niños o adolescentes se encuentran realmente rehabilitados. Se trata como vemos de un largo camino hacia la justicia en el que surgen siempre dudas, controversias, evoluciones e involuciones.

La Suprema Corte de los Estados Unidos al interpretar la Constitución fija la ruta ideológica del sistema en su conjunto. Las preguntas son 
muchas y variadas ¿ Debe tener un temperamento neutro o ideológico? ¿Debe la Suprema Corte ser un factor de cambio? ¿ Lo debe ser de estabilidad institucional? ¿Debe su presidente tratar de alcanzar decisiones unánimes? ¿Las decisiones unánimes fortalecen o debilitan a una corte suprema? Algunas de estas preguntas podrían aplicarse a la Suprema Corte mexicana.

La juez Sonia Sotomayor fue ratificada por el Senado. Es altamente probable que Elena Kagan sea también ratificada como la cuarta mujer en la Suprema Corte y la tercera en la Corte de Obama. Es probable que ocurran otras vacantes en la Suprema Corte, que darían al presidente Obama la capacidad para reforzar al grupo liberal de jueces que en los últimos años ha estado en minoría. La jueza asociada Ruth Bader Ginsburg tiene una grave enfermedad y por ello Obama tendría la posibilidad de nominar a un tercer candidato. Para entonces es también probable que la composición del Senado cambie y que los conservadores pretendan mantener su bastión judicial.

En los Estados Unidos designan a los jueces asociados de la Suprema Corte de por vida. En México las designaciones son por 15 años. Es decir el tiempo impone su jerarquía inapelable. En esta tan grata y animada reunión académica estoy a punto de rebasar el tiempo que me fue asignado por lo que les expreso mi agradecimiento por su amable atención y los invitó a leer y consultar Cuestiones Constitucionales, Revista Mexicana de Derecho Constitucional. 